\title{
Self-reported and informant-reported memory functioning and awareness in patients with mild cognitive impairment and Alzheimers disease
}

\author{
Martina Rios Silva · Doris Moser · Melanie Pflüger · Gisela Pusswald · Elisabeth Stögmann · Peter Dal-Bianco • \\ Eduard Auff · Johann Lehrner
}

Received: 30 March 2016 / Accepted: 5 May 2016 / Published online: 13 June 2016

(C) The Author(s) 2016. This article is available at SpringerLink with Open Access

\begin{abstract}
Summary
Background Awareness of subjective memory is an important factor for adequate treatment of patients with mild cognitive impairment (MCI) and Alzheimer's disease $(\mathrm{AD})$. This study served to find out whether awareness of subjective memory complies with objective performance, if differences in awareness are observed longitudinally and whether decrease of awareness can serve as a predictor of $\mathrm{AD}$ in MCI patients.

Methods Thirty-four patients with MCI seeking help in a memory outpatient clinic were included. All participants underwent thorough neuropsychological examination. Awareness of subjective memory was obtained by calculating difference scores between patient and informant ratings on a 16-item questionnaire concerning complaints about loss of memory in every-day life. Retesting was performed after a mean follow-up period of 24 months.

Results Whole group analyses showed that awareness remained relatively stable across time. Self-reported memory complaints correlated with episodic memory at baseline and with performance on a language task at follow-up. Retests displayed decrease of awareness. At group level differences in awareness between both times of assessment were not significant for MCI and MCI patients converting to mild $\mathrm{AD}$ at follow-up. The predictive value of awareness was low.
\end{abstract}

D. Moser · M. Pflüger · G. Pusswald ·

E. Stögmann · P. Dal-Bianco $\cdot$ E. Auff .

Ass. Prof. Priv. Doz. Mag. Dr. J. Lehrner $(\varangle)$

Department of Neurology, Medical University of Vienna,

Währinger Gürtel 18-20, 1097 Vienna, Austria

E-Mail: johann.lehrner@meduniwien.ac.at

M. R. Silva

Faculty of Psychology, University of Vienna, Vienna, Austria
Conclusions Awareness of subjective memory deficit is linked to episodic memory function and decreases with decline of cognitive ability. Further studies evaluating predictive power of awareness of subjective memory should include a larger patient sample.

Keywords Anosognosia · Awareness · Subjective memory assessment - Alzheimer's disease - Mild cognitive impairment

Subjektive Gedächtnisbeschwerden und Awareness bei Patienten mit leichter kognitiver Beeinträchtigung und Patienten mit Alzheimer Demenz

\section{Zusammenfassung}

Grundlagen Die Einsicht (Awareness) hinsichtlich der Erinnerungsleistung ist ein wichtiger Faktor für eine angemessene Behandlung von Patienten mit leichter kognitiver Beeinträchtigung (MCI) und AlzheimerKrankheit (AD). Ziel der vorliegenden Studie war herauszufinden (i) ob subjektive Gedächtnisleistung und objektive Gedächtnisleistung assoziiert sind, (ii) ob sich die Einsicht (Awareness) hinsichtlich der Erinnerungsleistung mit der Zeit verändert und (iii) ob die Einsicht (Awareness) hinsichtlich der Erinnerungsleistung ein Prädiktor für die Entwicklung einer Demenz ist.

Methodik Vierunddreißig Patienten mit MCI, die Hilfe in einer universitären Gedächtnisambulanz suchten, wurden in die Studie eingeschlossen. Alle Teilnehmer wurden einer ausführlichen neuropsychologischen Untersuchung unterzogen. Die Einsicht (Awareness) hinsichtlich der Erinnerungsleistung wurde durch Berechnung der Differenzwerte zwischen Patient und Informant Bewertung auf einem 16-Punkt-Fragebogen hinsichtlich Gedächtnisbeschwerden im täglichen Leben erhalten. Eine Kontrolluntersuchung wurde 
nach einer mittleren Nachbeobachtungszeit von 24 Monaten durchgeführt.

Ergebnisse Die Analyse zeigte, dass die Einsicht (Awareness) hinsichtlich der Erinnerungsleistung relativ stabil über die Zeit blieb. Selbst berichtete Gedächtnisbeschwerden korrelierten mit der episodischen Gedächtnisleistung zu Beginn der Studie und mit der Leistung bei einer Sprachaufgabe bei der Nachuntersuchung. Wiederholungsprüfungen angezeigt Rückgang des Bewusstseins. Der prädiktive Wert der Einsicht (Awareness) hinsichtlich der Erinnerungsleistung in Bezug auf die Demenzentwicklung war gering.

Schlussfolgerungen Einsicht (Awareness) hinsichtlich der Erinnerungsleistung ist mit episodischer Gedächtnis-Funktion verknüpft und nimmt mit Abnahme der kognitiven Fähigkeiten ab. Weitere Studien zur Vorhersagekraft der Einsicht (Awareness) hinsichtlich der Erinnerungsleistung sollten eine größere Patientenstichprobe umfassen.

Schlüsselwörter Anosognosia · Awareness · Subjektive Gedächtnisbeschwerden · Leichte kognitive Störung • Alzheimer Demenz

\section{Introduction}

Elderly people often experience cognitive decline with aging. The reasons for cognitive dysfunctions can range from physiological mild forgetfulness described by many older individuals to mild cognitive impairment until the severe effects of Alzheimer's disease [1]. Many patients with considerable subjective memory complaints (SMC) seek help at a memory outpatient clinic, and complaints increase from cognitive healthy elderly to patients with mild cognitive impairment (MCI) [2]. On the other hand, many patients with mild cognitive impairment (MCI) and Alzheimer's disease $(\mathrm{AD})$ do not recognize cognitive, functional or behavioral impairment [3]. But this anosognosia [4] can have serious effects on health, because patients eventually deny adequate treatment due to their unawareness of deficits. Daily functioning may be compromised, because they lack adequate judgement of situations [5].

Subjective memory complaints (SMC) are supposed to be an early symptom of dementia and therefore are often applied in the diagnostic process [6]. Cognitive decline is often accompanied by a change of awareness of deficits. Even in the earliest stages of AD and actually MCI, insight can be impaired and this lack of anosognosia is most common in severe $\mathrm{AD}[4,7]$. Vogel et al. [7] compared awareness of cognitive deficits in patients with MCI and mild $\mathrm{AD}$ and came to the conclusion, that impaired awareness was equally frequent in both groups with individual significant heterogeneity in the degree of impaired insight. Different studies regarding awareness in MCI demonstrate a great variability among this patient group. While some people with MCI show limited awareness, others seem to overestimate their dysfunction (also declared as reflecting heightened or hyper-awareness). Depressive symptoms may have negative influence on the expression of awareness and may increase negative attributions, making memory problems seem more severe than they are [2, 8]. Sevush and Leve [9] found, that denial of deficits might protect against depression in Alzheimer's disease, because unawareness was inversely related to depressed mood. Therefore informants are often involved in diagnosis and assessment of subjective memory awareness [10].

A review concerning self and informant reports in MCI patient illustrates that informant ratings display greater loss of cognitive competency and everyday functional ability and a greater correlation with objective measures of patient cognitive performance and characteristics of probable conversion to dementia [10]. Ecklund-Johnson and Torres [4] reviewed studies regarding unawareness of deficits in $\mathrm{AD}$ and found that unawareness of deficits progresses over time and awareness discrepancies between patients and their caregivers increase. Although informant reports might be influenced negatively by caregiver burden, informant ratings have turned out to be a strong predictor of an underlying dementia. The authors also conclude that memory deficits alone neither explain nor predict unawareness of deficits in $\mathrm{AD}$. Brain correlates of unawareness in dementia were mainly detected in frontal and tempo-parietal regions, but further research is needed [3].

The current research succeeds a recent cross-sectional study by Lehrner et al. [11]. They concluded that awareness decreases along the nonamnestic $\mathrm{MCI} \rightarrow$ amnestic $\mathrm{MCI} \rightarrow \mathrm{AD}$ continuum. The main objective of the present longitudinal study was to find out, whether awareness of subjective memory in patients with MCI has predictive value for future conversion to $\mathrm{AD}$. The methods were based on precedent studies using additional informant ratings [7]. The first aim was to explore correlations between subjective memory assessment and objective results of neuropsychological testing. Correlation analyses comprised neuropsychological test results and demographic data. Two variables measuring depressive symptoms were also included in order to examine the influence of depression on awareness $[2,8]$. The second aim was to figure out differences in awareness longitudinally. We hypothesized that small differences across time would indicate an intact awareness system, while large differences would reveal loss of awareness. It was assumed that decline of cognitive performance combined with decline of awareness between both times of assessment would imply anosognosia as observed in inherent dementia [4]. The final intent was to find out, if unawareness of memory deficits could serve as a predictor of future $\mathrm{AD}$ in patients with MCI. 


\section{Methods}

\section{Subjects and procedure}

The current study is part of a larger research project, the Vienna Conversion to Dementia Study. The data of this quasi-experimental longitudinal study were collected at the Department of Neurology of the Medical University Vienna. The study protocol has been approved by the Ethical Committee of the Medical University of Vienna and written informed patient consent to perform this study was received.

\section{Patients}

The study is based on a sample of 34 consecutive patients aged 50 years or older, who came to the memory outpatient clinic of the Medical University of Vienna due to self or informant reported memory problems and who fulfilled the inclusion criteria. They were either referred by physicians, by the Department of Neurology, or they were self-referrals. All patients went through clinical examination and neuropsychological testing. Exclusion criteria were evidence of stroke, traumatic head injury in the past, or other neurological disease, current psychiatric diagnosis according to ICD-10 [12] and any medical condition leading to cognitive deterioration. However, patients with depressive symptoms suggesting "depressive episode" according to ICD-10 were included, because these frequently appear in elderly people [2].

By means of a multi-group design, patients were divided into the subgroups aMCI, naMCI and AD after completion of the evaluation. MCI-subtypes were chosen according to Petersen et al. [13], using a cutoff score of 1, 5 standard deviations below age and education. AD was diagnosed according to DSM-IV criteria [14] and the NINCDS-ADRDA [15]. Additional informant ratings about subjective assessment of memory were included in the study.

\section{Measures}

\section{Neuropsychological Test Battery Vienna (NTBV)}

After a detailed anamnesis interview including standard questions about memory functions and a short survey of the accompanying person, the Mini Mental Status Examination (MMSE) [16] was performed. Additionally, all patients were subjected to the Neuropsychological Test Battery Vienna (NBTV) [17]. Patients with a MMSE score of less or equal 23 were excluded from the study. The NBTV includes tests for attention, executive functioning, language, and memory domains with corresponding $\mathrm{z}$-scores and was found to have very good discrimination power in detecting dementia [17]. Attention is assessed using the AltersKonzentrationstest (AKT) [18], a geriatric cancellation test, the digit symbol subtest of the German WAIS-R [19] and the symbol counting subtest from the cerebral insuffiency test (C.I.) [20]. The Trail Making Test B [21] and the score difference of the Trail Making Test A and $\mathrm{B}$ are also used to measure attention. The Trail Making Test A [21] is applied to investigate the executive function, which was also assessed by the FivePoint-Test [22], the Maze Test and the Stroop Test from the NAI Battery [23] and the interference test from the C.I. [20]. Lexical verbal fluency is investigated by naming as many words beginning with the letters $b, f$, and 1 that come to mind within one minute for each task. Language functions are tested by use of a verbal fluency tasks and a confrontation naming task [24]. Semantic and verbal fluency is assessed by naming as many animals, supermarket items and tools that came to mind within one minute for each task. The modified Boston Naming Test (mBNT) [25] is submitted for testing naming capabilities. Episodic memory is applied using the Verbal Selective Reminding Test (VSRT) [26] with the subtests of immediate recall, total recall, delayed recall, and recognition.

\section{Cognitive functioning (intelligence-quotient; IQ)}

The Wortschatztest (WST) [27], a standardized vocabulary test was applied to assess crystallized intelligence of all participants. The WST is a standardized vocabulary test, which is commonly used to examine verbal comprehension in patients with brain damage or dementia. See Table 1 for results.

\section{Assessment of subjective memory complaint}

Subjective memory problems were assessed by use of the Forgetfulness Assessment Inventory (FAI) scale [2]. The questionnaire consists of 16 questions concerning subjective memory difficulties in daily life within the past four weeks. Measurement is based on a 5 point Likert scale. Questions are e.g. "How often did you have problems during the past 4 weeks remembering ... e.g. names of people. $1=$ never, 2 = rarely, 3 = sometimes, $4=$ often, 5 = very often." Other items include memory difficulties concerning telephone numbers, faces, birthdays or shopping lists (for specific items see Appendix, Table A). The average of all 16 items represents a global score of memory complaints, which ranges from 0 to 5 . Higher scores indicate worse subjective memory performance and greater complaints. Accompanying persons were asked to fill in the informant version of the FAI in order to appraise memory functioning of the concerned patient (www.meduniwien.ac.at/kpfg). The FAI has been shown to have good psychometric test criteria [2]. See Table 1 for results. 
Table 1 Demographic characteristics of basic sample $(n=34)$

\begin{tabular}{|c|c|c|}
\hline & naMCl & aMCl \\
\hline$n$ & 15 & 19 \\
\hline Age & $70(55-79)$ & 71 (57-85) \\
\hline Male/Female & $8 / 7$ & $9 / 10$ \\
\hline Education & $8(5-15)$ & $8(8-17)$ \\
\hline MMSE & $28(26-30)$ & $27(24-30)$ \\
\hline $\mathrm{BDI}$ & $10(2-19)$ & $5(0-27)$ \\
\hline GDS & $3(0-8)$ & $2(0-10)$ \\
\hline FAl Self & $2.56(1.38-3.38)^{\mathrm{a}}$ & $2.88(1.38-4.06)^{b}$ \\
\hline FAl Informant & $3.12(1.31-4.62)$ & $2.84(1.63-4.38)$ \\
\hline Awareness & $-0.61(-2.31-1.75)^{a}$ & $-0.20(-2.50-2.25)^{b}$ \\
\hline
\end{tabular}

Table 2 Rates of conversion in aMCl and naMCl $(n=34)$



\section{Assessment of depressive symptoms}

Depressive symptoms were tackled by use of the Beck Depression Inventory (BDI-II) [28] and the Geriatric Depression Scale (GDS) [29]. The BDI-II consists of 21 items that ask about how often one felt certain ways within the past two weeks, rating on a fourpoint scale. Scores above 13 are consistent with clinical depressive symptoms. The BDI-II has been successfully used for screening depressive symptoms [36]. The GDS is a 15-item self-assessment questionnaire, which was developed to identify depression in the elderly. Participants are asked how they felt over the past week. The questions can be answered yes or no, with higher scores representing higher depressive symptoms. Scores above 5 are consistent with clinical depressive symptoms. The GDS has been successfully used for screening depressive symptoms [37]. See Table 1 for results.

\section{Awareness}

Awareness scores were assessed by subtraction of FAI informant rating scores from self rating scores. Positive signs imply that participants underestimated their memory functions in relation to their caregivers, negative signs suggest patients' overestimation. It is assumed that higher discrepancy scores indicate greater unawareness $[7,8]$. See Table 1 for results.

\section{Statistical Methods}

Demographic variables are described by median and range due to skewed distribution. At first step, cor- relations were calculated to compare whole-group FAI self, informant and awareness scores with objective performance measures and non-cognitive factors. Spearman correlations were chosen, because most of the NTBV-variables were not normally distributed. Second, whole-group comparisons of subjective memory assessment between baseline and follow-up were made using Pearson correlations. Normal distribution was verified by Kolmogorov-Smirnov test. At third step, differences across time were calculated at group-level. Wilkoxon signed-rank test was used to calculate differences across time within the MCI and AD diagnoses groups, because the assumptions of equal group-sizes and normal distribution for calculating repeated measures ANOVA were violated. Finally, Receiver operator characteristics analysis (ROC) was conducted in order to evaluate predictive value of FAI variables. Statistical analyses were performed using SPSS (version 22). The reported $p$-values result from two-tailed tests and are statistically significant at the level of $p<0.05$. Effect-sizes are reported according to Cohen [30], interpreting a correlation coefficient of $r=0.10$ as small effect, $r=$ 0.30 as medium effect and $r=0.50$ as large effect.

\section{Results}

\section{Descriptive data}

A total of 34 patients between 55 and 85 years $(M d n=$ 70 years) were assessed at a 2-year follow-up ( $M d n=$ 28 months). Altogether, 17 males (50\%) and $17 \mathrm{fe}-$ males $(50 \%)$ were included in the study. Mean duration of formal education was 8 years, ranging from 
Table 3 Spearman's correlation coefficients $\left(r_{s}\right)$ between FAl self, informant and awareness scores, objective performance measures and non-cognitive factors

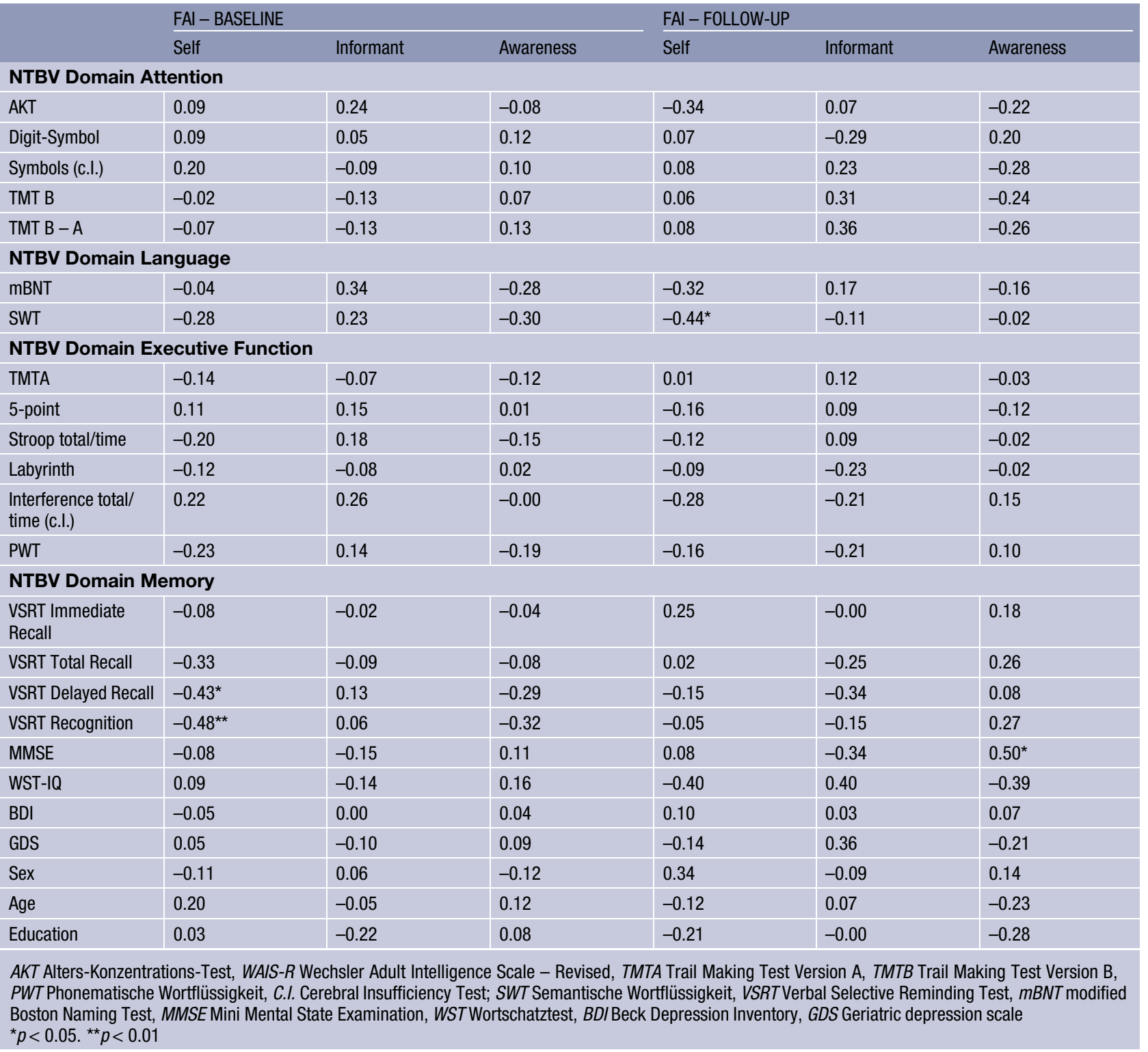

5 to 17 years. At the baseline 34 patients were diagnosed as MCI, 19 of them were classified as aMCI, 15 as naMCI according to Petersen [13]. See Table 1 for details. At follow up 13 patients $(38,2 \%)$ converted to $\mathrm{AD}, 4$ of them were male, 9 female. Table 2 presents conversion rates including the MCI subgroups aMCI and naMCI. Within the group of baseline diagnosis aMCI, 11 people $(57,9 \%)$ turned to $\mathrm{AD}$, while only 2 of the initial naMCI patient group (13,3\%) were diagnosed as $\mathrm{AD}$ at follow up.

\section{Correlations whole group with objective test data}

Spearman correlations were performed to compare FAI self, informant and awareness scores with objective performance measures and non-cognitive factors at both times of testing. The results including the single NTBV subtests are presented in Table 3. They show a wide variation of correlations of FAI self and informant ratings with objective performance scores (NTBV, MMSE and WST), but only 3 of them are significant. Negative correlations indicate that lower objective performance scores were in line with higher memory complaints concerning self and informant questionnaires or vice versa. Regarding self-assessment at baseline, there were two significant negative correlations with the NTBV subtests Verbal Selective Reminding Test (VSRT) - delayed recall and VSRT-recognition, which belong to the domain memory. At follow-up one significant negative correlation was found in the domain language. All significant correlation coefficients showed moderate effects (all $r_{\mathrm{s}}$ : 0.30 to 0.50 ) according to Cohen [30]. 
Table 4 Pearson correlations between baseline and follow-up for FAl self, informant and awarenessscores; means and standard deviations

\begin{tabular}{|c|c|c|c|c|c|}
\hline & $r$ & $M$ & $S D$ & $n$ & \\
\hline \multirow[t]{2}{*}{ Self } & $0.55^{\star \star}$ & 2.76 & 0.70 & 32 & $\mathrm{~T} 1$ \\
\hline & & 2.81 & 0.59 & 22 & $\mathrm{~T} 2$ \\
\hline \multirow[t]{2}{*}{ Informant } & $0.50^{\star \star}$ & 3.07 & 0.92 & 34 & $\mathrm{~T} 1$ \\
\hline & & 3.03 & 0.98 & 32 & $\mathrm{~T} 2$ \\
\hline \multirow[t]{2}{*}{ Awareness } & $0.51^{*}$ & -0.33 & 1.14 & 32 & $\mathrm{~T} 1$ \\
\hline & & -0.29 & 1.20 & 20 & T2 \\
\hline
\end{tabular}

Table 5 Median scores of FAI self, informant and awareness ratings for $\mathrm{MCl}$ and $\mathrm{AD}$ across time

\begin{tabular}{|c|c|c|c|c|c|c|c|c|}
\hline & \multicolumn{4}{|c|}{ Baseline } & \multicolumn{4}{|c|}{ Follow-up } \\
\hline & \multicolumn{2}{|l|}{$\mathrm{MCl}$} & \multicolumn{2}{|c|}{$\mathrm{MCl}-\mathrm{AD}$} & \multicolumn{2}{|l|}{$\mathrm{MCl}$} & \multicolumn{2}{|l|}{$A D$} \\
\hline & $M d n$ & $n$ & $M d n$ & $n$ & $M d n$ & $n$ & $M d n$ & $n$ \\
\hline Self & 2.75 & 18 & 3.01 & 4 & 2.81 & 18 & 2.60 & 4 \\
\hline Informant & 2.88 & 19 & 3.75 & 13 & 3.00 & 19 & 3.69 & 13 \\
\hline Awareness & -0.10 & 16 & -0.61 & 4 & 0.17 & 16 & -1.31 & 4 \\
\hline
\end{tabular}

Table 6 ROC analysis, $\mathrm{MCl}$ conversion to $\mathrm{AD}$

\begin{tabular}{|l|l|l|l|l|l|}
\hline & AUC & $S$ & $p$ & $95 \% \mathrm{KI}$ & + \\
\hline Self assessment & & & - & 0.36 & 0.85 \\
\hline Informant assessment & 0.60 & 0.12 & 0.33 & 0.41 & 0.82 \\
\hline Awareness & 0.62 & 0.11 & 0.29 & 0.21 & 0.64 \\
\hline AUC Area under the ROC Curve & 0.42 & 0.11 & 0.46 & & \\
\hline
\end{tabular}

Correlation analyses of FAI awareness scores revealed a wide range of correlations with objective performance scores (NTBV, MMSE and WST). There was one significant positive correlation with the MMSE at follow up. The significant positive association indicated that overestimation was associated with lower performance on MMSE. Its correlation coefficient showed a large effect $\left(r_{\mathrm{s}}=0.50\right)$.

Concerning non-cognitive factors, one significant positive correlation with moderate effect was found between informant scores and the Geriatric depression scale (GDS) at follow up, indicating that higher informant estimated memory complaints were associated with an increase of patient's depressive symptoms. The demographic variables sex, age at onset and education did not reveal significant correlations regarding FAI self, informant and awareness scores.

\section{Total group correlations across time}

Total group Pearson correlations between baseline and follow up were calculated to compare FAI self, informant and awareness scores between both times of testing. All correlation coefficients were statistically significant (all $p<0.01$ ) with large effect (all $r \geq 0.50$ ). See Table 4 for details.

\section{Differences among $\mathrm{MCl}$ and $\mathrm{AD}$ patient groups across time}

The two groups of MCI patients, who turned to $\mathrm{AD}$ and those whose remained MCI at follow-up, were examined for overall differences in FAI scores between both times of assessment by use of a Wilcoxon signedrank test. Median scores are presented at Table 5. Wilcoxon signed-rank tests did not reveal significant differences for patients who remained diagnosed as MCI for FAI self $(Z=-1.23, p=0.22)$, informant $(Z=$ -1.07, $p=0.29)$, and awareness $(Z=-1.03, p=0.30)$ ratings between both times of assessment. Those patients who turned to $\mathrm{AD}$ at follow-up, also did not reveal significant difference scores between baseline and follow-up for FAI self $(Z=-0.37, p=0.72)$, informant $(Z=-0.73, p=0.46)$, and awareness $(Z=$ $-0.73, p=0.47$ ) ratings. Regarding self and informant assessment median scores, memory complaints raised in the MCI group and decreased for those patients, who turned to $\mathrm{AD}$ at follow up. Concerning awareness, discrepancy scores between self and informant questionnaires decreased slightly for the MCI group and increased for those, who were diagnosed as $\mathrm{AD}$ at the second time. In summary, the results of the present analyses could not provide evidence that 
awareness changes longitudinally within the diagnosis subgroups of MCI or MCI converting to AD.

\section{Prediction of $A D$}

Finally Receiver-Operating-Characteristics (ROC) analysis was performed to explore the relative predictive power of FAI self, informant and awareness rating to detect dementia onset in the following 2 years. The Area under the ROC curve $(A U C)$ is used as an indicator of the discriminative utility of each type of awareness assessment. An area of 1 represents a perfect test, while random guessing produces an area of 0.5 [31]. FAI self, informant and awareness ratings of MCI patients at the baseline were compared with $A D$ conversion-rates at follow-up. The results of the ROC analyses revealed an $A U C$ of 0.60 for self and 0.62 for informant questionnaires indicating poor discriminative utility. Awareness discrepancy scores had similar predictive power $(A U C=0.42)$. See Table 6 for details.

\section{Discussion}

The main intention of the present study was to explore awareness of subjective memory assessment in patients with MCI and $\mathrm{AD}$ and to determine if unawareness can serve as a predictor for future conversion to $\mathrm{AD}$ in MCI. For this purpose, objective performance measures were compared to patient and caregiver memory reports and to awareness scores on two times of assessment with a mean interval of two years. Awareness was assessed by subtracting informant-rating from self-rating scores of the FAI questionnaire. Whole-group comparisons of awareness with objective test data revealed one significant correlation concerning overall cognitive ability (MMSE), which became significant with large effect at followup $\left(r_{\mathrm{s}}=0.50\right)$. Patients with decline of cognitive performance overestimated their memory function compared to their caregivers. This outcome supports studies indicating that unawareness increases with cognitive decline $[4,11]$. Whole-group comparisons between self-assessment FAI scores and the results of the NTBV revealed significant correlations with subtests of the domains memory and language. At baseline self-ratings yielded two significant associations with moderate effect to the VSRT-subtests Delayed Recall $\left(r_{\mathrm{s}}=-0.43\right)$ and Recognition $\left(r_{\mathrm{s}}=-0.48\right)$ of the domain memory, revealing intact good accordance. The VSRT assesses loss of episodic memory, which is a core diagnostic criterion for later conversion to AD [32]. Lehrner et al. [11] used the subtest Delayed Recall of the VSRT as a measure of objective memory in order to obtain awareness scores, because it is very sensitive to age related memory decline. Its association with self-assessment scores at baseline supports studies stating that memory complaints are supposed to be an early manifestation of memory impairment [33]. At follow-up, this correlation was not significant any- more, instead self-report correlated significantly with the Semantic Word Fluency Test (SWT, $r_{\mathrm{s}}=-0.44$ ) of the domain language. People who had worse performance on this test complained more about loss of memory. One reason might be a decline of insight for memory impairment in patients with proceeding MCI and those who converted to AD, while insight to dysfunctions in other cognitive domains remains relatively intact in early stages of dementia [7]. Nevertheless, correlations with awareness scores, as observed in anosognosia, were not significant for these subtests of the NTBV [4]. One probable explanation is that patients, who converted to dementia at followup, showed mild symptoms of AD because patients scoring 23 or less on the MMSE were excluded from the study. Unlike expected, informant memory appraisals did not correlate significantly with memory tasks at any time of assessment. As mentioned above, informant follow-up ratings rather reflected decline of overall cognitive ability. Besides, difference scores at group level showed that informant FAI scores revealed better memory appraisals for the $\mathrm{AD}$ group at follow-up than at the baseline. Nevertheless, discrepancy scores increased, because patients overestimated their memory functions even more [7]. These findings might be influenced by several aspects like sample size, patient-informant relationship and characteristics of informants. Moreover, the current study did not include patients with moderate or severe $\mathrm{AD}$, where memory deficits can easily be detected by caregivers. Neurocognitive memory tasks might identify subtle cognitive changes which might be beyond the competence of informants [10].

In the field of non-cognitive factors, sex, age and education did not reveal any effect on awareness. Whole-group comparisons of the underlying sample could not reveal evident influence of depressive symptoms on awareness. More longitudinal studies are needed to investigate effects of hyper-awareness or underestimation [8].

Another question of interest was, whether awareness changed over time in the total sample and each diagnostic group separately. Whole-group correlation analyses between baseline and follow-up showed that awareness of subjective memory assessment remained stable over time. Significant correlation coefficients with large effect (all $r_{\mathrm{s}} \geq 0.5$ ) revealed that patients as well as their caregivers estimated patient-concerned memory functions consistently between baseline and follow-up. These results suggest that awareness of subjective memory assessment remains relatively stable in MCI and early $\mathrm{AD}$ patients. Separate group analyses also revealed that neither MCI nor AD-converted patients differed significantly across time regarding self, informant and awareness scores. These findings are supported by previous studies claiming that the level of awareness does not differ significantly between patients with MCI and mild AD [7]. Subjective memory complaints 
increased in those people who maintained the MCI diagnosis and decreased those who converted to AD. The increase of discrepancy scores within the $\mathrm{AD}$ group indicates a decline of awareness in $\mathrm{AD}$ patients who tend to overestimate their memory functions. Although not significant, these findings correspond to the significant correlates of awareness with MMSE scores. They support precedent studies indicating that decline of overall cognitive ability is associated with decrease of awareness [4, 11]. Regarding conversion rates within the MCI patient group, 11 of 13 people who turned to $\mathrm{AD}$ at follow-up, were diagnosed as aMCI at the baseline. Only 2 initial naMCI patients received the diagnosis of $\mathrm{AD}$ at the second time of assessment. These results are in line with previous studies claiming that people with aMCI are at higher risk of conversion to $\mathrm{AD}[34,35]$.

One major objective of the present study was to find out the predictive power of subjective memory assessment. FAI self, informant and awareness ratings of MCI patients who converted to $\mathrm{AD}$ or remained MCI were subject to ROC analyses. ROC curve analyses revealed that all ratings were close to random guessing (all $A U C<0.65$ ). Therefore the present study could not confirm the hypothesis that awareness of subjective memory assessment serves as predictor for future dementia. Regarding the small sample size of self and awareness scores these results have to be interpreted with caution.

The present study has some limitations. First, the sample size was generally limited due to the design of the study. Patients with moderate or severe AD were not included in the study, because they are not capable of filling in the self-assessment questionnaires. Due to the small sample size only a limited number of patients converted to $\mathrm{AD}$, thus, the study was probably statistically underpowered. However, the results of the study may generate new research questions using larger clinical sample sizes. Second, as this was a clinical study, its results may not be generalizable to the general population. Third, another limitation of the study was, that depressive symptoms/psychiatric di- agnosis were not assessed by psychiatric (diagnostic) interview. Finally, information about cognitive trainings, drug or other treatments against probable progression to $\mathrm{AD}$ between both times of testing, that might have influenced the outcome [34], was not assessed in the study.

The strengths of the study are the profound neuropsychological examination of all patients and the satisfactory sample size despite clinical limitations. Given the fact that cognitively well-preserved MCI patients usually come alone to the clinical assessment at the memory clinic, the number of participants plus informants performing pre- and post-tests is remarkable.

In conclusion, our study demonstrates that MCI patients have a relatively intact awareness of memory performance and a good self-estimation regarding episodic memory. In the longer term, cognitive decline leads to a decrease of complaints about memory loss, and to an increase of discrepancy scores between patients and their caregivers. Generally speaking, unawareness of subjective memory deficit increases to some extent in patients with incipient $\mathrm{AD}$, but further long-term research is needed to clarify the relationship between awareness and $\mathrm{AD}$.

\section{Compliance with ethical guidelines}

Conflict of interest M.R. Silva, D. Moser, M. Pflüger, G. Pusswald, E. Stögmann, P. Dal-Bianco, E. Auff and J. Lehrner state that there are no conflicts of interest.

Ethical standards The study protocol has been approved by the Ethical Committee of the Medical University of Vienna and written informed patient consent to perform this study was received.

Open Access This article is distributed under the terms of the Creative Commons Attribution 4.0 International License (http://creativecommons.org/licenses/by/4.0/), which permits unrestricted use, distribution, and reproduction in any medium, provided you give appropriate credit to the original author(s) and the source, provide a link to the Creative Commons license, and indicate if changes were made. 


\section{Appendix}

Table A Forgetfulness Assessment Inventory (FAI) self-report

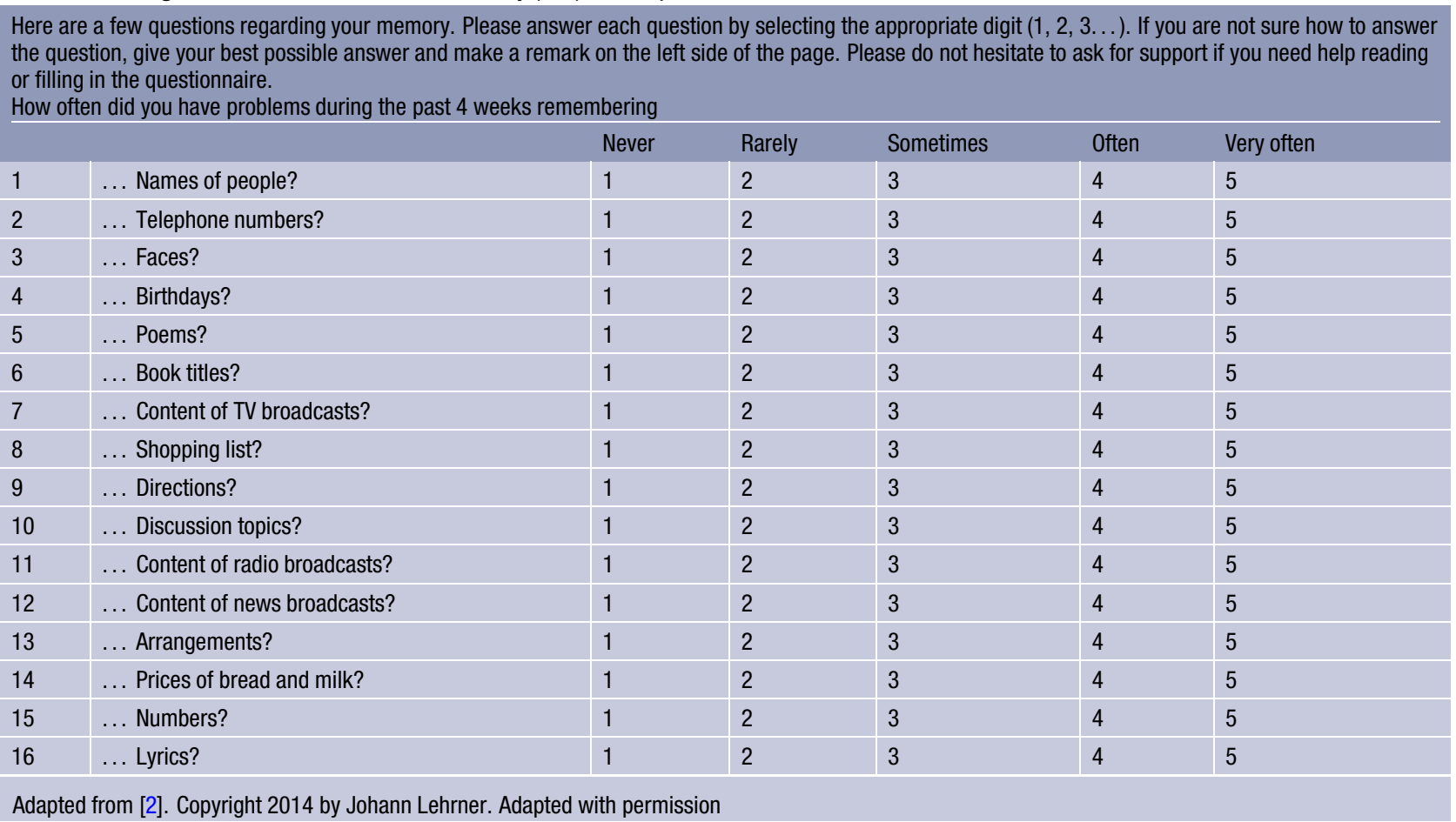

\section{References}

1. Saxton J, Morrow L, Eschman A, Archer G, Luther J, Zuccolotto A. Computer assessment of mild cognitive impairment. Postgrad Med. 2009;121(2):177-85.

2. Lehrner J, Moser D, Klug S, GleißA, et al. Subjective memory complaints, depressive symptoms and cognitionin patients attending a memory outpatient clinic. Int Psychogeriatr. 2014;26(3):463-73. doi:10.1017/S1041610213002263.

3. Zamboni G, Wilcock G. Lack of awareness of symptoms in people with dementia: the structural and functional basis. Int J Geriatr Psychiatry. 2011;26(8):783-92. doi:10.1002/gps.2620.

4. Ecklund-Johnson E, Torres I. Unawareness of deficits in Alzheimer's disease and other dementias: operational definitions and empirical findings. Neuropsychol Rev. 2005;15(3):147-66. doi:10.1007/s11065-005-9026-7.

5. AaltenP,ValenEvan,ClareL,KennyG, VerheyF.Awarenessin dementia: a review of clinical correlates. Aging Ment Health. 2005;9(5):414-22. doi:10.1080/13607860500143075.

6. Abdulrab K, Heun R. Subjective memory impairment. A review of its definitions indicates the need for a comprehensive set of standardised and validated criteria. Eur Psychiatry. 2008;23(5):321-30. doi:10.1016/j.eurpsy.2008.02.004.

7. Vogel A, Stokholm J, Gade A, et al. Awareness of deficits in mild cognitive impairment and Alzheimer's disease: do MCI patients have impaired insight? Dement Geriatr Cogn Disord. 2004;17(3):181-7. doi:10.1159/000076354.

8. Roberts JL, Clare L, Woods RT. Subjective memory complaints and awareness of memory functioning in mild cognitive impairment: a systematic review. Dement Geriatr Cogn Disord. 2009;28(2):95-109. doi:10.1159/000234911.

9. Sevush S, Leve N. Denial of memory deficit in Alzheimer's disease. Am J Psychiatry. 1993;150(5):748-748.
10. Schinka JA. Use of informants to identify mild cognitive impairment in older adults. Curr Psychiatry Rep. 2010;12(1):4-12. doi:10.1007/s11920-009-0079-9.

11. Lehrner J, Kogler S, Lamm C, et al. Awareness of memory deficits in subjective cognitive decline, mild cognitive impairment, Alzheimer's disease and Parkinson's disease. IntPsychogeriatr. 2015;27(03):357-66.

12. Dilling H, Mombour W, Schmidt MH, Internationale Klassifikation Psychischer Störungen. ICD-10 KapitelV (F). Klinisch-diagnostische Leitlinien, 4th edn. Bern: Huber; 2000.

13. Petersen RC. Mild cognitive impairment as a diagnostic entity. J Intern Med. 2004;256(3):183-94. doi:10.1111/j.13652796.2004.01388.x.

14. Saß H, Wittchen HU, Zaudig M, Houben I. Diagnostisches und statistisches Manual psychischer Störungen. Göttingen: Hogrefe; 2003, Textrevision-DSM-IV-TR.

15. McKhann G, Drachman D, Folstein M, Katzman R, Price D, Stadlan EM. Clinical diagnosis of Alzheimer's disease: report of the NINCDS-ADRDA work group under the auspices of department of health and human services task force on Alzheimer's disease. Neurology. 1984;34:939-44.

16. Folstein MF, Folstein SE, McHugh PR. Mini-mental state: a practical method for grading the cognitive state of patients for the clinician. J Psychiatr Res. 1975;12(3):189-98.

17. Lehrner J, Maly J, Gleiß A, Auff E, Dal-Bianco P. Demenzdiagnostik mit Hilfe der Vienna Neuropsychologischen Testbatterie (NTBV): Standardisierung, Normierung und Validierung. Psychol Osterreich. 2007;4(5):358-65.

18. Gatterer G. Alters-Konzentrations-Test (AKT). Göttingen: Hogrefe; 1990.

19. Tewes U. Hamburg-Wechsler-Intelligenztest für Erwachsene Revision 1991 (HAWIE-R). Bern: Hans Huber; 1994. 
20. Lehrl S, Fischer B. Kurztest für cerebrale Insuffizienz (c.I.Test), 5th ed. Ebersberg: Vless; 1997.

21. Reitan RM. Trail making test: manual for administration and scoring. Tucson: Reitan Neuropsychology Laboratory; 1979.

22. Regard M, Strauss E, Knapp P. Children's production on verbal and non-verbal fluency tasks. Percept Mot Skills. 1982;55(7):839-44.

23. Oswald WD, Fleischmann UM. Das Nürnberger-AltersInventar. Göttingen: Hogrefe; 1997.

24. Goodglass H, Kaplan P. The assessment of aphasia and related disorders. Philadelphia: Lea \& Fabinger; 1983.

25. Morris JC, Heyman A, Mohs RC, Hughes JP, Van Belle G, Fillenbaum G. The Consortium to Establish a Registry for Alzheimer's Disease (CERAD). Part I. Clinical and neuropsychological assessment of Alzheimer's disease. Neurology. 1989;39(9):1159-65.

26. Lehrner J, Gleiß A, Maly J, Auff E, Dal-Bianco P. Der Verbale Selektive Reminding Test (VSRT). Ein Verfahren zur Überprüfung verbaler Gedächtnisfunktionen. Neuropsychiatrie. 2006;20:204-14.

27. Schmidt KH, Metzler P. Wortschatztest (WST). Weinheim: Beltz Test; 1992.

28. Hautzinger M, Keller F, Kühner C. Beck DepressionsInventar (BDI-II). Frankfurt: Harcourt Test Services; 2006.

29. Sheikh JI, Yesavage JA. 9/Geriatric Depression Scale (GDS). Recent evidence and development of a shorter version. In: BrinkTL, editor. Clinicalgerontology: aguide to assessment and intervention. New York: Haworth; 1986. pp. 165-73, $5(1-2)$.
30. Cohen J. Statistical power analysis for the behavioral sciences, 2nd ed. Hilldale: Lawrence Erlbaum Associates; 1988.

31. Fawcett T. An introduction to ROC analysis. Pattern RecognitLett. 2006;27(8):861-74.

32. BäckmanL, Jones S, Berger AK, LaukkaEJ, Small BJ. Multiple cognitive deficits during the transition to Alzheimer's disease. J Intern Med. 2004;256(3):195-204.

33. Jorm AF, Christensen H, Korten AE, Jacomb PA, Henderson AS. Memory complaints as a precursor of memory impairment in older people: a longitudinal analysis over 7-8 years. PsycholMed. 2001;31(3):441-9.

34. Gauthier S, Reisberg B, Zaudig M, et al. Seminar mild cognitive impairment. Lancet. 2006;367(9518):1262-70.

35. Lehrner J, Gufler R, Guttmann G, Maly J, et al. Annual conversion to Alzheimer disease among patients with memory complaints attending an outpatient memory clinic: The influence of amnestic mild cognitive impairment and the predictive value of neuropsychological testing. Wien Klin Wochenschr. 2005;117:629-35. doi:10.1007/s00508-0050428-6.

36. Steer RA, Cavalieri TA, Leonard DM, Beck AT. Use of the Beck depression inventory for primary care to screen for major depression disorders. Gen Hosp Psychiatry. 1999;21:106-11.

37. Lin X, Haralambous B, Pachana NA, Bryant C, LoGiudice D, Goh A, Dow B. Screening for depression and anxiety among older Chinese immigrants living in Western countries: the use of the Geriatric Depression Scale (GDS) and the Geriatric Anxiety Inventory (GAI). Asia Pac Psychiatry. 2016;8(1):32-43. 